\title{
The Balanced Scorecard as a Performance Management Tool for Third Sector Organizations: the Case of the Arthur Bernardes Foundation, Brazil
}

\author{
Ricardo Corrêa Gomes * \\ E-mail address: rgomes@ufv.br \\ Departamento de Administração/Universidade Federal de Viçosa \\ Viçosa, MG, Brazil.
}

\section{Joyce Liddle}

E-mail address: joyce.liddle@ntu.ac.uk

International Centre for Public Services Management/Nottingham Business School

Nottingham, United Kingdom.

\begin{abstract}
The aim of this paper is to contribute to the theory of public management by presenting empirical evidence of using the Balanced Scorecard for third sector organizations. The research was conducted within an interpretive paradigm using an action research strategy. Data was collected through focus group and individual interviews and analyzed using interpretation and content analysis. The main limitation of this study lies in its application to a very singular type of organization that operates as a driver to improve the efficiency and nimbleness of other public organizations, although the methods employed here are very likely to be applicable to other kinds of organizations without adversely affecting the results. The findings corroborate Kaplan and Norton's (2001) suggestion that non-profit organizations should put customers at the top of their strategic maps. They also indicate that sponsors should be considered a strong stakeholder in the strategic plan, and need to be satisfied in order to ensure legitimacy and sustainability. Although some authors have suggested that an overall framework should be devised for an entire organization, the evidence indicates that developing a single Balanced Scorecard for each department promotes cooperation rather than competition and leads to synergy rather than fragmentation.
\end{abstract}

Key words: non-profit sector; third-sector organizations; balanced scorecard; action research; case studies.

Received 07 August 2008; received in revised form 17 March 2009.

Copyright (C) 2009 Brazilian Administration Review. All rights reserved, including rights for translation. Parts of this work may be quoted without prior knowledge on the condition that the source is identified.

\footnotetext{
* Corresponding author: Ricardo Corrêa Gomes

Universidade Federal de Viçosa, Avenida Peter Henry Rolfs, s/n, Campus Universitário, 36570-000, Viçosa, MG, 35670-000, Brazil.
} 


\section{INTRODUCTION}

In Brazil, third-sector organizations play an important role in helping the government to formulate policies, deliver services and enhance both flexibility and agility in public management processes. For this reason, there are several types of third-sector organizations attached to the three levels of government (federal, state and local). One important type of public service delivered by the federal government is higher education, which is mainly carried out by public universities. As public entities, these institutions have to comply with the requirements set down by the Government. To support them in their activities, they need a support mechanism in the form of a foundation to help them, within the legal framework, to secure funding from public and private organizations, to manage contracts, to purchase goods from internal and external markets and to account for all expenses to the funding organizations. This support foundation can be seen as a kind of tugboat, helping the public universities to manoeuvre in confined waters.

The Balanced Scorecard [BSC] is a strategic planning tool developed by Kaplan and Norton (1996) as a response to the assumption that organizations only exist to satisfy stockholders (Kaplan \& Norton, 1992). It is based on a four dimensional framework, where each dimension represents a different set of stakeholders: Learning and Growth; Internal Business Processes; Customers; and Finance (Kaplan \& Norton, 1996, p. 9). According to the authors, the BSC is based on the rationale that skilled employees will improve process quality and cycle time, which therefore leads to on-time delivery and customer loyalty. At the end of the chain of improvements, the organization is very likely to achieve higher returns on investments and, consequently, shareholder satisfaction (Kaplan \& Norton, 1996, p. 31). In other words, the BSC is a performance management framework whose main contribution to the literature is to enlarge the number of interested parties and actors within the process.

In this paper, we will present the experience of using the Balanced Scorecard as a planning and performance appraisal tool for helping third sector organizations to:

. Define objectives and targets;

. Define performance measures;

. Define actions for ensuring performance improvement; and

. Ensure the institutionalization of a virtuous quality improvement cycle.

According to Kaplan and Norton (1992, p. 72) the BSC helps organizations to answer the following four questions:

1) How do customers see us? (Customer perspective)

2) What must we excel at? (Internal perspective)

3) Can we continue to improve and create value? (Innovation and learning perspective)

4) How do we view our shareholders? (Financial perspective)

As an example of the third sector, the organization used as an illustrative case study does not aim to produce a profit. Rather, it is concerned with managing resources to foster research results at a lower cost and to act as a tugboat for public universities by improving efficiency and nimbleness. For this specific situation, Kaplan and Norton (2001, pp. 98-99) suggested that, "For a nonprofit or government agency, however, the financial measures are not the relevant indicators of whether the agency is delivering on its mission. The agency's mission should be featured and measured at the highest level of its scorecard". 
This paper aims to contribute to the public management literature by offering practical as well as theoretical reflections that will help think tank organizations to manage better. The main objective of the study presented here is to test whether Kaplan and Norton's Balanced Scorecard can help this type of organization to improve performance.

The paper is structured as follows: first we will present the theoretical background. Then, we present the research methodology, indicating the philosophical approach guiding the investigation, data collection and analysis, as well as the research strategy. After this, the results and analysis are presented. Finally, some concluding remarks relating to the theoretical and practical contribution of the research are presented.

\section{THEORETICAL BACKGROUND}

Public sector organizations have increased their use of performance indicators [PI] as a tool for monitoring, managing and measuring performance. PIs have been devised from several different tools and frameworks, such as the Business Excellence Model, Investors in People, charter mark, ISO 9000, the balanced scorecard and benchmarking (McAdam, Hazlett, \& Casey, 2005). An alternative list of performance management frameworks was suggested by Lee (2006): the Performance Pyramid, the Results and Determinants Matrix, the Balanced Scorecard, the Consistent Performance Measurement System, and the Integrated Performance Measurement System. The common point between the two lists is Kaplan and Norton's (1996) Balanced Scorecard.

According to Kaplan and Norton (1996, p. 25), "The Balanced Scorecard translates mission and strategy into objectives and measures, organized into four different perspectives: financial, customer, internal business process, and learning and growth". They (Kaplan \& Norton, 1996, p. 25) also add that, "The four perspectives of the scorecard permit a balance between short-and long-term objectives, between outcomes desired and the performance drivers of those outcomes, and between hard objective measures and softer, more subjective measures". In Kaplan and Norton's view (1996), strategies are developed following a cause and effect approach. In this vein, "The measurement system should make the relationships (hypotheses) among objectives (and measures) in the various perspectives explicit so that they can be managed and validated" (Kaplan \& Norton, 1996, p. 30). For example, investments in learning will lead to a better internal business process, which, in turn, is likely to improve a customer's satisfaction and loyalty, and therefore result in a higher return on investments, which would satisfy shareholders (Kaplan \& Norton, 2001).

Now that it has been implemented in a large number of business-based organizations, we intend to apply it to public organizations. There is evidence within literature that the BSC has been employed in the USA and Canada (Chan, 2004), Great Britain (Wisniewski \& Olafsson, 2004), New Zealand (Greatbanks \& Tapp, 2007), and Norway (Askim, 2004), among other countries. Despite being widespread in developing countries, there is little empirical evidence reported in the literature of the application of the BSC in developing countries, and no evidence whatsoever for the specific case of Brazilian small-scale municipalities.

Lee (2006, p. 52) argues that the following characteristics legitimise the BSC as a useful framework for improving performance:

. Derived from strategy;

Stimulates continuous improvement;

Clearly defined purpose;

Simple to understand and use. 
According to Kaplan and Norton (2001), the BSC needs some adjustments in order to fit to the modus operandi of not-for-profit organizations, because their main objectives are not finance-related. They suggest putting the customer at the top of the strategic map. However, even this small alteration could be a complicated one. Kaplan and Norton (2001, p. 98), argue that "in a nonprofit organization, donors provide the financial resources - they pay for the service - while another group, the constituents, receives the service. Who is the customer - the one paying or the one receiving?" In order to address this strategic problem, they suggest that:

Rather than have to make such a Solomonic decision, organizations place both the donor perspective and the recipient perspective, in parallel, at the top of their Balanced Scorecards. They develop objectives for both donors and recipients, and then identify the internal processes that deliver desired value propositions for both groups of "customers" (Kaplan \& Norton, 2001, p. 98).

Radnor and Lovell (2003) developed some key-measures that need to be met in order to ensure the successful implementation of the BSC in Health Care Organizations in the UK:

. Demonstrate the BSC's theoretical and practical potential to add service value;

. Obtain support to introduce the BSC;

Do not ignore past experiences.

In the same vein, Chan (2004, p. 216) concluded that it was important to make the effort to put the BSC in public organizations using a set of eight factors:

. Top management commitment and leadership buy-in;

. Departmental, middle-manager and employee participation and buy-in;

. Culture of performance excellence;

. Training and education;

. Keeping it relatively simple, easy to use and understand;

. Clarity of vision, strategy and outcome;

. Link balanced scorecard to incentive; and

. Resources to implement system.

Lee (2006) proposed a systemic performance management framework based on the four dimensions of the BSC, having public schools as a research locus. Another example of using the BSC in public organizations is Petrobras (Petroleum Prospecting and Trading Agency, a public joint stock company whose main shareholder is the Federal Government) (Villas, Fonseca, \& Macedo-Soares, 2006). The BSC has also been employed in voluntary organizations involved in health services (Moullin, 2004a, 2004b; Moullin et al., 2007) and higher education (Chen, Yang, \& Shiau, 2006).

Though widely used in the private and public sectors, there is still a need to investigate the BSC as a strategy for performance management for non-profit organizations, mainly in developing countries. Based on the ideas presented above, this study aims to test whether the BSC can help to improve the performance of third-sector organizations and the impact of employing it as a performance management framework. 


\section{METHODS}

Due to the relative scarcity of interpretive studies within third-sector management literature, we carried out exploratory research, focusing on the implementation of the BSC as a strategy and performance management framework in this type of organization. The focal organization was the Arthur Bernardes Foundation [FUNARBE], which was founded to support the Federal University of Viçosa, securing funding from public and private organizations, managing contracts, purchasing goods from internal and external markets and accounting for expenditure to the funding organization.

Following the interpretive philosophy, data were collected through an action research approach (Bryman, 2004; Lee \& Lings, 2008; Mumford, 2001) with the agreement and the active participation of managers, directors and staff. Semi-structured interviews, participant observation and focus groups were used to collect information. Data were analyzed according to a joint approach involving researchers and participants, employing content analysis (Bryman, 2004; Lee \& Lings, 2008). The process started in September 2006, when the group met to devise the strategic plan for the year of 2007. This process was repeated in September 2007, when objectives, targets and performance indicators were reviewed and updated.

\section{FINDINGS}

\section{The Case at a Glance}

FUNARBE is an organization with 300 employees located on the edge of the Federal University of Viçosa's campus. The university is 140 miles from Belo Horizonte, which is the capital of the State of Minas Gerais. The Foundation was established in 1979 to support the research activities of the university.

The Foundation has a simple three-level administrative structure, as illustrated in Figure 1. At the strategic level, responsible for the definition of the main policies, is the Administrative Council, which works as the board of the foundation. The board is composed of seven executive and six non-executive members. Among the seven executive councillors there is an ex officio position for the Pro-Rector of Research. Councillors are all members of the university and can be academics, lecturers or other civil servants from the university. They are selected by a ballot of the fellows of the university. Below the Administrative Council, there is the Fiscal Council, which is also made up of academics and employees of the university. The Fiscal Council supports the Administrative Council in relation to accounting issues. 


\section{Figure 1: FUNARBE's Organizational Chart}

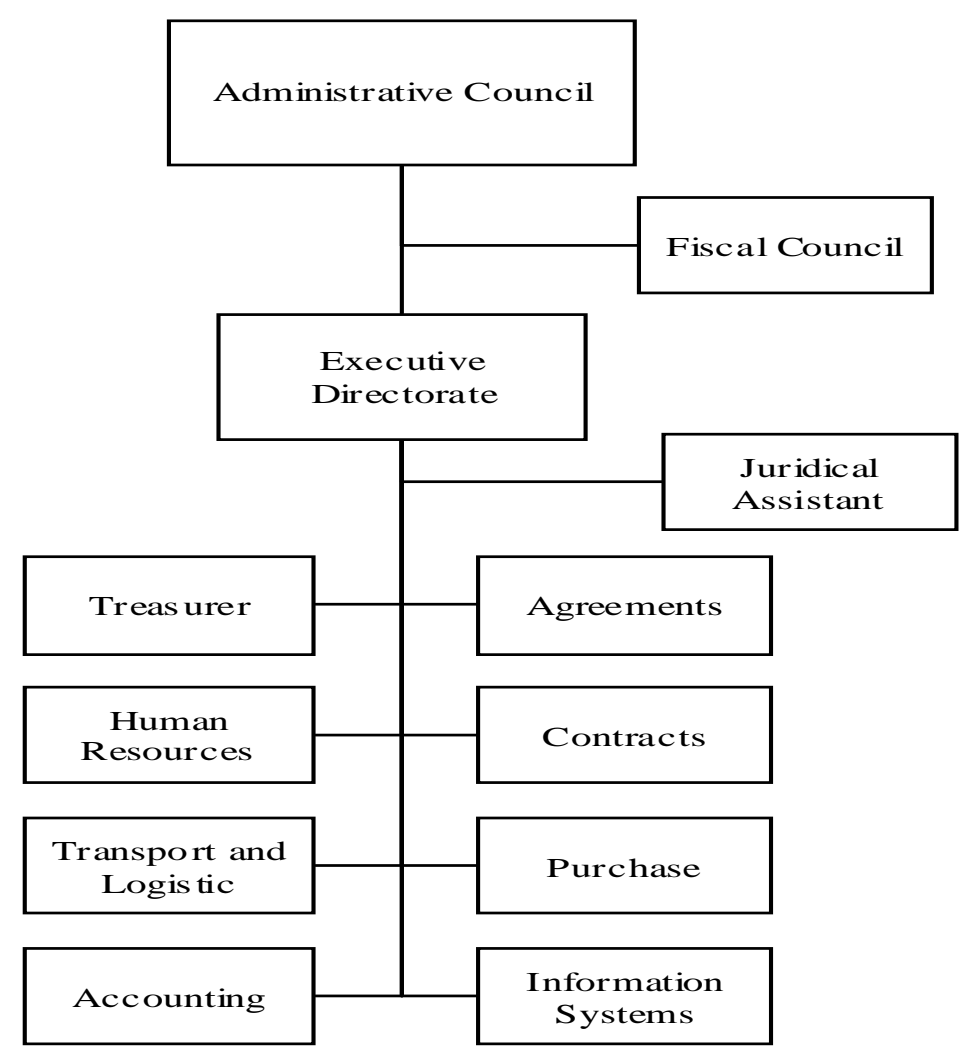

Source: developed by the authors.

The Executive Directorate is elected from among the University's senior lectures for a four-year term of office and is responsible for the daily activities and decisions, such as planning, organizing, directing, and controlling. Among the activities managed by the Executive Directorate are the management of contracts and agreements with government agencies and private sector organizations; hiring, developing, training, and evaluating the performance of employees and staff; and controlling investments in order to keep the foundation financially healthy.

At the operational level, there are eight departments responsible for the daily activities of the Foundation: Agreements (contacts with public funding agencies); Contracts (contacts with private funding agencies); Purchasing; Accounting; Treasury; Information Systems; Human Resources; Transportation and Logistics. In addition to the administrative structure, and directly accountable to the Executive Directorate, there is the Juridical Assistant.

\section{ACTION RESEARCH FINDINGS}

In this section, we present the results as they were gathered from the inductive investigation. In order to simplify the presentation, these will be described in chronological order. 


\section{First Year}

The first meeting took place in 2006 when the administrative structure, namely the Executive Directorate and the Heads of Departments, gathered together to define the strategic plan for the year of 2007. At that time, a new Executive Directorate had been elected and the directorates wished to define a new mission, vision, objectives and actions to ensure the long term survival of FUNARBE.

Table 1: FUNARBE's Strategic Map for the Year 2007

\begin{tabular}{|c|}
\hline Dimensions \\
\hline Finance \\
\hline Customers
\end{tabular}

Source: developed by the authors.

After a full day of discussions, the first BSC map was developed and the group decided to put the finance dimension at the top as Table 1 illustrates. This choice was prompted by some contingent problems the third sector had been facing in Brazil since 2005, when Foundations suffered a loss of confidence due to fraud discovered in the accounting of the University of Brasília's Foundation.

After this first meeting, the heads of departments were in charge of developing at least one objective, one target and one performance indicator for each strategy in the BSC, as it affected their department. Although this had the disadvantage of flooding the management system with performance indicators, this choice was made to ensure the transformation of each department into a single business unit.

After a week of discussion with their teams, the staff returned their objectives, targets, performance indicators and actions for achieving them. As a result of this endeavour, more than 50 objectives were proposed. At that time, we did not worry too much about the large number, because this was the first time they were participating in the strategic planning process and performance measures were part of their daily activities.

\section{Second Year}

In September 2007, the team (with some modifications to its composition) was gathered again in a different venue to start the strategic planning process, now for a long-term period (2008-2013). The meeting started with each Head of Department presenting his or her results so far. After that, the group was called to make an evaluation of the whole process and the benefit/damage done to the management process. According to their experience and discourses, the results were very good. The Heads of Departments were confident that the BSC framework had helped to focus on objectives, and performance indicators were important tools for helping to control performance and targets.

As a result and after a small ballot, the group decided to maintain the BSC as a strategy and performance management framework. At that time, the Executive Directorate put the following guidelines to be followed in the period ahead on the table: 
. To improve FUNARBE's image as a reference of managing agreements and contracts;

. To extend affirmative action towards FUNARBE being acknowledged as a supporting entity to the Federal University of Viçosa;

. To seek alternative sources of resources due to the reduction in private funds;

. To reduce the legal and procedural vulnerabilities;

. To fit FUNARBE's action within a sustainable framework;

. To improve the human resource development processes.

Table 2: FUNARBE's Main Objectives for the Year 2008 According to the BSC Rationale

\begin{tabular}{|c|c|c|}
\hline DEPARTMENT & DIMENSION & OBJECTIVE \\
\hline \multirow{4}{*}{ Agreements } & Finance & To improve income \\
\hline & Customer & To improve customer satisfaction \\
\hline & Internal Processes & To improve the information system \\
\hline & Learning and Growth & To train employees on specific agreement legislation \\
\hline \multirow{4}{*}{ Contracts } & Finance & To improve incomes \\
\hline & Customer & To improve customer satisfaction \\
\hline & Internal Processes & To create the conditions to diversify portfolio \\
\hline & Learning and Growth & To train employees in negotiation processes \\
\hline \multirow{4}{*}{ Purchase } & Finance & To improve income from the importation process \\
\hline & Customer & To improve customer satisfaction \\
\hline & Internal Processes & To improve the efficiency of the purchasing system \\
\hline & Learning and Growth & To train employees in negotiation processes \\
\hline \multirow{4}{*}{$\begin{array}{l}\text { Information } \\
\text { Systems }\end{array}$} & Finance & To reduce costs \\
\hline & Customer & To improve customer satisfaction \\
\hline & Internal Processes & To maximize computer systems resources \\
\hline & Learning and Growth & To improve employees skilfulness \\
\hline \multirow{4}{*}{$\begin{array}{c}\text { Human } \\
\text { Resources }\end{array}$} & Finance & To reduce costs \\
\hline & Customer & To improve customer satisfaction \\
\hline & Internal Processes & To improve the internal communication system \\
\hline & Learning and Growth & $\begin{array}{l}\text { To train employees to act as developing human resources rather } \\
\text { than controlling mechanisms }\end{array}$ \\
\hline \multirow{4}{*}{ Accounting } & Finance & To reduce operation costs \\
\hline & Customer & To improve customer satisfaction \\
\hline & Internal Processes & To improve the efficiency of the accounting report processes \\
\hline & Learning and Growth & $\begin{array}{l}\text { To update employees' knowledge of legislation and formal } \\
\text { procedures }\end{array}$ \\
\hline \multirow{5}{*}{ Finance } & \multirow{2}{*}{ Finance } & To reduce bank tariffs \\
\hline & & To improve the profitability of investments \\
\hline & Customer & To improve customer satisfaction \\
\hline & Internal Processes & To reduce the number of checks issued \\
\hline & Learning and Growth & To train employees on investments \\
\hline \multirow{4}{*}{$\begin{array}{c}\text { Transport and } \\
\text { Logistic }\end{array}$} & Finance & To reduce costs \\
\hline & Customer & To improve customer satisfaction \\
\hline & Internal Processes & To implement the inventory control system \\
\hline & Learning and Growth & To improve employees skilfulness \\
\hline
\end{tabular}

Source: developed by the authors.

One week after the meeting, the group was gathered together to present their objectives, targets, and actions. The results were very good this time, because they had learned from their mistakes. Just one Head of Department had proposed more than one objective for each dimension of the BSC. The rest of the group linked to the objectives set before and had focused on defining more adequate targets and 
better performance indicators that were aligned with the guidelines proposed. As a result, the number of objectives had fallen substantially and the level of integration among them increased (Table 1 presents the final list). According to the findings, managers did not want to see their performance levels dropping, because they suspected that the performance indicator framework would be used as a basis for a future remuneration policy.

According to their testimony, some departments had promoted meetings with other departments in order to search alignment among objectives. This was a fine and unpredicted result of the process. When the Executive Directorate proposed different sets of objectives the idea behind the action was to transform each department into a single business unit. The first feeling was that it could bring about competition between departments, but that did not happen. On the contrary, they began to seek means for improving their performance together rather than tearing themselves to pieces to gain advantage in relation to one another.

Instead of competing with each other for financial resources and legitimacy, the management team liaised in order to devise common objectives which would be more easily attained with less effort (Law of Least Effort). As a result of this behaviour, ideas were discussed to improve the quality of the service provided and to challenge the processes carried out. One can easily see the evidence for this process in the list of objectives provided in Table 2.

The synergy and cooperation which resulted from alignment of mission, objectives and actions, which we regard as the result of the application of the BSC, helped the Foundation to improve its performance by achieving a higher surplus, developing a better image in the eyes of service users, and a better image in the eyes of the Administrative and Fiscal Councils. The surplus allowed the Foundation to put into practice some positive actions for the benefit of the university community: a new bursary scheme for undergraduate research students, support for newly founded research degree programmes, and bursaries for recent doctorates.

Other managerial results of the BSC scheme are:

. The level of staff motivation is higher than ever (measured by turnover figures);

- The quality of services provided is good, according to a survey carried out among service users (we shall deal with this issue elsewhere); and

. The number of services rejected dropped to almost zero, according to each department's internal figures.

\section{FinAL REMARKS AND CONCLUSIONS}

The Balanced Scorecard has been largely used as strategy and performance framework in private sector organizations throughout the world. After the introduction of New Public Management, it started to be used in public and non-profit organizations in order to facilitate the performance management process. In spite of the increase in the number of studies about its usefulness and uselessness for the private sector, there is still a need to test the feasibility of the BSC as a management framework in the government and non-profit domain.

This paper presented an ongoing investigation being carried out through action research, focusing on a Brazilian third-sector organization. The main aim of the investigation was to corroborate the fitness of the BSC as a strategy and performance framework for this kind of organization. The locus of the investigation was the Arthur Bernardes Foundation, which was created to support the Federal University of Viçosa in its relationships with public and private funding agencies. 
The findings demonstrate that there are some departments whose operational nature allowed managers to understand the BSC rationale better. Others did not have the same facility for doing so, which resulted in the setting of unachievable objectives, inappropriate targets and hard-to-measure performance indicators. This problem arose because of the lack of experience of some department heads, some of whom had never participated in a strategic planning process before.

When the process was reviewed, managers acknowledged that the BSC helped them to devise viable plans and also allowed them to manage their departments better. There was a consensus across the management team and an acceptance that the results from the BSC performance indicators provided a useful basis for launching a 'performance remuneration regime', to be introduced in the course in 2008.

The findings gathered in this research corroborate the assumption that an organization should develop a different Balanced Scorecard for each business unit rather than create an overall framework for the whole organization. The evidence is quite overwhelming that an individual Balanced Scorecard for each unit induced cooperation rather than competition and synergy rather than fragmentation.

We reached another interesting conclusion from the observations gathered throughout the analysis which has to do with the BSC strategic map, as illustrated in Figure 2. According to Kaplan and Norton (2001), government and non-profit organizations should put the customer or citizen at the top of their strategic map because this type of organization does not seek profits. Our conclusion is that FUNARBE does not pursue profits, although it does desperately need financial stability in order to survive, which is ensured by good financial performance. Besides satisfying the Administrative and the Fiscal Councils, FUNARBE needs to face the University as a strong stakeholder whose demands need to be met, and it needs to be assured that the financial resources obtained from public and private funding agencies are being managed in a wise and safe way. By securing these ends, it will be possible to secure the Foundation's financial health in the long term. 
Figure 2: FUNARBE's Strategic Map for the Year 2008

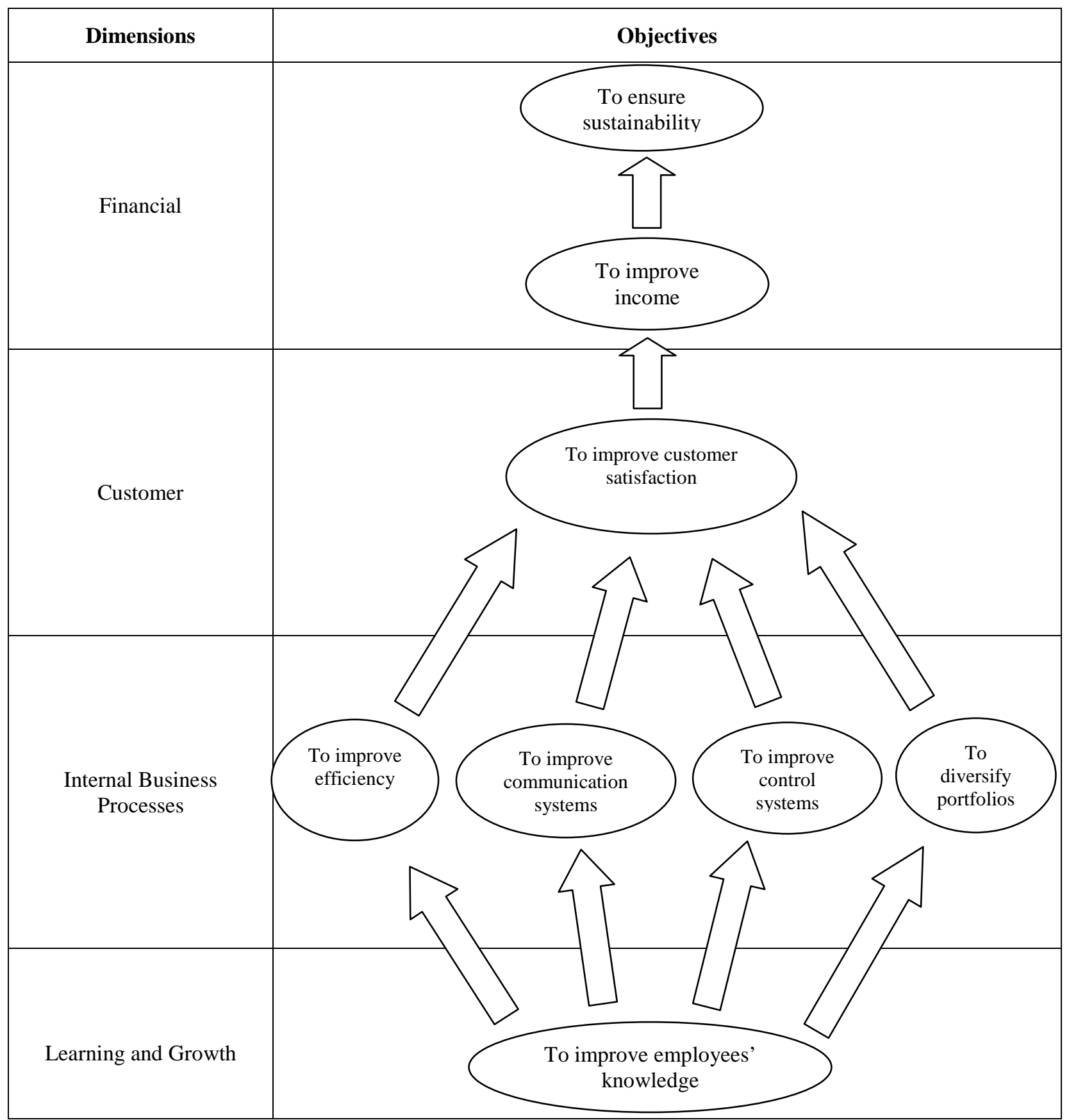

Source: developed by the authors.

This argument supports the assumption that sponsors are also an important stakeholder in non-profit organizations, and may even be as important as customers are. Moreover, sustainability and institutional support are another important dimension for measuring the performance of non-profit organizations. 


\section{ACKNOWLEDGEMENTS}

Many thanks to Fundação Arthur Bernardes for the opportunity in special to its Executive Directorate and to its staff without whose support this investigation was not possible.

\section{REFERENCES}

Askim, J. (2004). Performance management and organizational intelligence: adapting the balanced scorecard in larvik municipality. International Public Management Journal, 7(3), 415-438.

Bryman, A. (2004). Social research methods. Oxford: Oxford University Press.

Chan, Y. C. L. (2004). Performance measurement and adoption of balanced scorecards: a survey of municipal governments in the USA and Canada. International Journal of Public Sector Management, 17(3), 204-221.

Chen, S. H., Yang, C. C., \& Shiau, J. Y. (2006). The application of balanced scorecard in the performance evaluation of higher education. The TQM Magazine, 18(2), 190-205.

Greatbanks, R., \& Tapp, D. (2007). The impact of balanced scorecards in a public sector environment Empirical evidence from Dunedin City Council, New Zealand. International Journal of Operations \& Production Management, 27(8), 846-873.

Kaplan, R. S., \& Norton, D. P. (1992). The balanced scorecard - Measures that drive performance. Harvard Business Review, 70(1), 71-79.

Kaplan, R. S., \& Norton, D. P. (1996). The balanced scorecard: translating strategy into action. Boston: Harvard Business School Press.

Kaplan, R. S., \& Norton, D. P. (2001). Transforming the balanced scorecard from performance measurement to strategic management: part I. Accounting Horizons, 15(1), 87-104.

Lee, N. (2006). Measuring the performance of public sector organisations: a case study on public schools in Malaysia. Measuring Business Excellence, 10(4), 50-64.

Lee, N., \& Lings, I. (2008). Doing business research: a guide to theory and practice. London: Sage Publications.

McAdam, R., Hazlett, S. A., \& Casey, C. (2005). Performance management in the UK public sector: addressing multiple stakeholder complexity. International Journal of Public Sector Management, 18(3), 256-273.

Moullin, M. (2004a). Eight essentials of performance measurement. International Journal of Health Care Quality Assurance, 17(3), 110-112.

Moullin, M. (2004b). Evaluating a health service taskforce. International Journal of Health Care Quality Assurance, 17(5), 248-257.

Moullin, M., Soady, J., Skinner, J., Price, C., Cullen, J., \& Gilligan, C. (2007). Using the public sector scorecard in public health. International Journal of Health Care Quality Assurance, 20(4), 281-289.

Mumford, E. (2001). Advice for an action researcher. Information Technology \& People, 14(1), 12-27. 
Radnor, Z., \& Lovell, B. (2003). Success factors for implementation of the balanced scorecard in a NHS multi-agency setting. International Journal of Health Care Quality Assurance, 16(2), 99-108.

Villas, M., Fonseca, M., \& Macedo-Soares, T. D. L. v. A. de (2006). Assegurando o alinhamento estratégico da tecnologia de informação e comunicação: o caso das unidades de refino da Petrobras. Revista de Administração Pública, 40(1), 127-153

Wisniewski, M., \& Olafsson, S. (2004). Developing balanced scorecards in local authorities: a comparison of experience. International Journal of Productivity and Performance Management, 53(7), 602-610. 